\title{
Capital social e políticas públicas na região metropolitana de Porto Alegre: comparando Novo Hamburgo e Estância Velha
}

\author{
Everton Rodrigo Santos
}

Marcello Baquero

\section{I ntrodução}

A partir da consolidação da democracia eleitoral, a qual determinou as regras do jogo político no Brasil, rotinizando as eleições nos seus diferentes níveis e garantindo o pluripartidarismo e a legitimidade jurídica das instituições, institucionalizou-se a poliarquia (Dahl, 1997). Entretanto, ao mesmo tempo, a legitimidade social que emana das percepções e comportamentos dos cidadãos não se materializou, produzindo uma situação assimétrica entre legitimidade jurídica e legitimidade societal. Nessas circunstâncias, se, por um lado, constata-se o avanço procedural da democracia, por outro, os gestores públicos enfrentam o desafio de satisfazer as crescentes demandas da sociedade por uma melhor qualidade de vida e bem-estar. Essas demandas pressionam as instituições do Estado e, consequentemente, as políticas públicas para que se tornem mais distributivas e eficazes. Diz respeito, portanto, às relações entre Estado e sociedade, buscando identificar quais são os fatores que influenciam as avaliações dos cidadãos em relação às políticas públicas municipais. Sob que condições as políticas públicas podem apresentar um desempenho considerado satisfatório para os governos locais?

Com base nessas indagações, este artigo objetiva analisar as razões que levam as pessoas a avaliar positivamente as políticas públicas no Rio Grande do Sul, em duas cidades da região metropolitana de Porto Alegre: Novo Hamburgo e Estância Velha. Esses dois municípios fazem parte do Corede do Vale do Rio dos Sinos (Conselho Regional de Desenvolvimento do Vale do Rio dos Sinos) e, no passado, pertenciam à cidade de São Leopoldo, conhecida por ser o "berço da imigração alemã" no estado.

A despeito de serem cidades originárias da mesma matriz de imigração alemã, apresentam diferenças em várias dimensões, especialmente, no seu timing de emancipação política institucional, no número de habitantes e nas dotações orçamentárias. Em Novo Hamburgo, por exemplo, há atualmente cerca de 240 mil 
habitantes, em Estância Velha, há somente 40 mil habitantes. No entanto, seus Índices de Desenvolvimento Humano (IDHs), 0,809 em Novo Hamburgo e 0,808 em Estância Velha, são praticamente iguais, de acordo com o último PNUD (2000). O que poderia explicar, então, as diferenças, quando se examina o seu desempenho em termos de políticas públicas? Que fatores poderiam facilitar as ações governamentais e consequentemente a implantação de políticas públicas em cada cidade analisada? Essas questões remetem para outra questão central: a eficiência, bem como a satisfação com um governo municipal, depende das instituições políticas ou da cultura política?

Objetivando responder a essas questões, examinamos primeiramente as características históricas e institucionais dos municípios estudados, atentando para o fato de ambos serem cidades diretamente ligadas à imigração alemã no Rio Grande do Sul no século XIX e terem suas emancipações recentes no século XX, caracterizando-se por serem municípios de médio e pequeno porte que tiveram na indústria calçadista seu principal mote de desenvolvimento até recentemente.

Em seguida, em "Políticas públicas, institucionalismo e culturalismo", problematizamos o debate a respeito da tradição dos estudos sobre políticas públicas no Brasil, sem perder de vista as discussões e controvérsias teóricas sobre as vertentes institucionalista e culturalista para explicar os avanços e recuos democráticos das sociedades (Dahl, 1997; Huntington; 1968; Almond e Verba, 1966). A primeira vertente no lato sensu dá ênfase aos aspectos políticos institucionais do Estado. Chama a atenção para o fato de que o bom desempenho de um governo democrático dependeria da institucionalização de regras formais; desse modo, considera que as instituições podem sim influir na sociedade, estruturando os comportamentos políticos e estimulando ou inibindo os atores para o desenvolvimento local. Por outro lado, argumentaremos que, a despeito da importância das instituições e de regras formais para o desenvolvimento democrático de uma sociedade, em virtude das deficiências dessas instituições em resolver os problemas de natureza material essencial, a cultura política passa a desempenhar papel significativo no funcionamento governamental local e, portanto, em suas políticas públicas. Nessa perspectiva, aproximando-nos mais do institucionalismo sociológico, que considera também as instituições informais, e assim abrindo um campo bem mais amplo do que aquele originalmente posto pelos institucionalistas históricos, desembocamos finalmente nos estudos da cultura política, argumentando que um bom governo depende dos costumes, dos valores de uma sociedade e das práticas políticas republicanas de seus cidadãos.

$\mathrm{Na}$ parte final do artigo, "A dimensão metodológica e empírica da pesquisa", demonstramos, após uma breve digressão da metodologia utilizada, que políticas públicas que encontram uma sociedade organizada, horizontalizada e detentora de capital social, portanto fértil socialmente, possuem melhores condições de obter êxito em seus 
propósitos, conforme os dados empíricos arrolados neste artigo em consonância com nosso quadro teórico de cultura política.

A hipótese que formulamos sugere que o capital social incide no desempenho dos governos e, consequentemente, de suas políticas públicas. A ser confirmada essa hipótese, poder-se-ia afirmar que o sucesso de reformas políticas e de investimentos públicos está relacionado não somente à qualidade das leis e à capacidade das instituições dos governos em implementá-las, mas também à qualidade do tecido social nas cidades examinadas. Desse modo, a relação entre capital social e satisfação das pessoas com as políticas públicas se constituiria num importante subsídio teórico analítico para o estabelecimento de uma relação mais eficiente entre Estado e sociedade.

\section{Características históricas e institucionais dos municípios estudados}

A partir do século XIX, mais precisamente em 1804, os portugueses promoveram a primeira divisão territorial do Rio Grande do Sul (na época Província de São Pedro do Rio Grande do Sul), criando inicialmente quatro municípios, com a finalidade de ocupar estratégica e militarmente a região: Rio Grande, Porto Alegre, Santo Antônio da Patrulha e Rio Pardo (Siedenberg, 2004). Assim, ao longo de sua história política, tivemos outras subdivisões, criando-se 88 municípios no século $\mathrm{XIX}$, inclusive o município de São Leopoldo, elevado à condição de vila em 1846 e de cidade em 1864, que incluía, naquela época, as atuais cidades de Novo Hamburgo e Estância Velha, objeto de nossa análise ${ }^{1}$.

Todavia, merece um especial destaque a configuração histórica desses municípios em tela. A despeito da importância destes para a região e o estado, poucos são os estudos existentes sobre suas trajetórias históricas ${ }^{2}$. Todos eles, no entanto, partem da história do município de São Leopoldo e de sua imigração alemã, visto que, por força de origem, ambos estão intimamente ligados a ele.

Na região que viria a ser São Leopoldo, em meados do século XVIII, foi estabelecida uma feitoria do lado esquerdo do Rio dos Sinos, destinada ao plantio de linho cânhamo ${ }^{3}$ por lusos e luso-brasileiros. Após a independência do Brasil, o governo imperial constituiu uma política de ocupação de áreas pouco povoadas, oportunizando que, em 1824, tivesse início a imigração alemã oficial na região a partir da chegada de menos de 40 imigrantes. Posteriormente, as estatísticas do período apontaram que, entre os anos 1824 e 1830, entraram cerca de 5.350 alemães no estado do Rio Grande do Sul

\footnotetext{
1 Mas é a partir da segunda metade do século $X X$ e início do XXI que se observa um crescimento vertiginoso dos municípios, chegando a 496 em 2013.

2 Particularmente sobre a cidade de Estância Velha, não há bibliografia acadêmica.

${ }^{3}$ As embarcações lusitanas utilizavam cordas e velas produzidas pela fibra dessa planta que era cultivada e trabalhada por escravos na Real Feitoria do Linho Cânhamo. Nessa região surgiram dezenas de fazendas que se destinavam à produção da matéria para a confecção de produtos desse estabelecimento. Uma dessas fazendas chamava-se Estância Velha, nome que designará a própria cidade posteriormente. Cf. Alves (2006)
} 
e entre os anos 1830 e 1889 foram introduzidos mais 20 mil imigrantes alemães, responsáveis pela criação de 142 colônias alemãs no estado (Anuário da Indústria e do Comércio de Novo Hamburgo, 2001/2002).

O projeto imperial destinava-se a atender à necessidade de criação de um grupo capaz de realizar o contraponto em uma sociedade estruturada com base numa aristocracia escravista, pecuarista e latifundiária e, ainda, que pudesse desenvolver uma policultura que abastecesse o mercado interno (Cunha, 2006). Assim, as condições peculiares da implantação da política de imigração no extremo sul do país possibilitaram a formação de pequenas propriedades rurais com mão de obra familiar (Lando e Barros, 1980).

Esse período caracterizou-se pela superação dos obstáculos provenientes do não cumprimento dos contratos e promessas realizados pelo governo imperial e seus agentes captadores de imigrantes. Não obstante os entraves, a cidade apresentou rápido e constante crescimento econômico, fomentado pela instalação da estrada de ferro que possibilitou a ligação da cidade com outras áreas da província, em especial, Porto Alegre, tornando-se paulatinamente um dos principais mercados fornecedores de produtos agrícolas do Rio Grande do Sul.

Nessa nova configuração,

os comerciantes ganharam destaque no centro urbano pelo sucesso financeiro que já haviam obtido. Seriam eles, junto com os brasileiros que detinham o poder político local, que formariam a elite do lugar (Ramos, 2006, p. 434).

Da mesma forma, tem-se o desenvolvimento de um processo de construção de identidade vinculada à ideia de pertencimento cultural à antiga nação e, consequentemente, à etnia alemã (Weber, 2004). Ramos (2006) postula que os imigrantes desenvolveram a ideia de pertencimento a uma etnia e a uma cultura própria, internamente delimitada e externamente reconhecida.

O processo de desenvolvimento econômico, ligado prioritariamente à agricultura, alavancou o desenvolvimento de atividades de comércio e indústria. Muitos dos imigrantes realizavam, em seu país de origem, ofícios outros que não o plantio. 0 isolamento e as necessidades da cidade permitiram o desenvolvimento de uma indústria incipiente que se irradiou pela região circunvizinha.

A indústria calçadista foi a atividade industrial que assumiu maior relevância na região do Vale do Rio dos Sinos e especialmente em Novo Hamburgo e Estância Velha, que ainda pertenciam ao município de São Leopoldo. Em 1898, Pedro Adams Filho inaugurou a primeira fábrica de calçados onde hoje é Novo Hamburgo, fomentando o surgimento de indústrias secundárias nessa localidade (Schemes et al., 2005). Nas 
primeiras décadas do século XX, a cidade contava com 66 indústrias de couro, com 1.180 operários e 590 máquinas (Rambo, 1956).

O município de Novo Hamburgo obteve sua emancipação em 5 de abril de 1927 e contabiliza atualmente uma população estimada em 247.781 habitantes espalhados em 223,8 quilômetros quadrados, com uma densidade demográfica de 1.067,5 habitantes por quilômetro quadrado (IBGE, 2013). A cidade de Estância Velha, vizinha de Novo Hamburgo, emancipou-se mais recentemente, em 8 de setembro de 1959, e possui uma área total bem menor, ficando com 52,4 quilômetros quadrados, possuindo também um número menor de habitantes, tem uma população estimada em 45.500, sendo 816,4 habitantes por quilômetro quadrado (IBGE, 2013).

Essas emancipações podem ser explicadas por duas razões básicas: uma pela necessidade que os governos estaduais tinham de garantir e obter maior representatividade na distribuição dos recursos federais e outra pelas demandas locais, ou seja, pelo crescimento demográfico, industrial, comercial e pelas necessidades de melhorias na infraestrutura urbana e qualificação dos serviços públicos (Siedenberg, 2004) ${ }^{4}$. Nesse sentido, as emancipações geraram situações novas, organizaram essas localidades com suas leis orgânicas, aproximando essas comunidades de sua estrutura estatal, canalizando de certa forma recursos para a região.

Paralelamente a esses novos arranjos institucionais, ao longo do século XX, haverá um processo de industrialização crescente no Vale do Rio dos Sinos, com a formação de polos industriais de referência nacional e internacional, como foi o caso da expansão do setor coureiro-calçadista, desde 1970 até meados dos anos de 1990, que viveu o auge da exportação de sapatos. Todavia, no final dos anos 1990, assistimos à queda desse setor coureiro-calçadista, com fechamento de fábricas e deslocamento de empresas para outras áreas do país a partir do fortalecimento da China como a segunda economia mundial e do aumento das importações.

Assim, um dos principais desafios postos no horizonte dessas cidades nas últimas décadas tem sido justamente a busca da superação dessa matriz centrada na "indústria calçadista" para poder alavancar o seu desenvolvimento. Nesse sentido, essas comunidades têm nos seus municípios e políticas públicas um aliado estratégico para esse empreendimento e, consequentemente, a superação de seus obstáculos. Acreditamos que as políticas públicas podem, através da distribuição de seus recursos, organizar uma comunidade de maneira menos desigual. Todavia, como veremos, essa "distribuição de recursos" de fato também vai depender das características societais encontradas numa determinada sociedade.

\footnotetext{
${ }^{4}$ Não podemos deixar de citar aqui também as disputas políticas locais como fontes de emancipações.
} 


\section{Políticas públicas, institucionalismo e culturalismo}

É importante destacar, conforme Souza (2006), que as políticas públicas correspondem a um campo teórico e metodológico que tem na ação do Estado seu principal escopo de estudo. Na tradição europeia dos estudos sobre políticas públicas, a preocupação residia no Estado e suas instituições, deixando em segundo plano a avaliação da produção dos governos. É somente com estudos realizados nos Estados Unidos que se cria uma tradição cuja ênfase se direciona para a ação dos governos, no âmbito da administração pública, tendo como pressuposto que o que o governo faz ou deixa de fazer é passível de ser analisado cientificamente (Pase e Santos, 2011; Souza, 2006).

No caso brasileiro, as produções acadêmicas que examinam as políticas públicas guardam uma tradição que remonta ao século $X X$ nas ciências sociais. De uma preocupação inicialmente com a explicação da formação do Estado Nacional que aparece em obras de vários intelectuais brasileiros, tais como Raimundo Faoro (1958), Oliveira Viana (1974), Sérgio Buarque de Holanda (1992), entre outros, o campo de análise propriamente de políticas públicas vai surgir no Brasil seguindo três tradições distintas de estudos ${ }^{5}$.

Como primeira tradição, temos as políticas públicas voltadas para os processos decisórios, a cidadania e o padrão de intervenção do Estado brasileiro. A preocupação aqui reside nos aspectos do policy-making na perspectiva de pensar o Estado desenvolvimentista, suas políticas industriais e o planejamento econômico. Dentre os inúmeros intelectuais que contribuíram para essa tradição, Lafer (1978), por exemplo, vai discutir a importância da construção do consenso para a eficácia dos mecanismos decisórios do Estado brasileiro, enquanto Santos (1979) atenta para a característica brasileira de uma "cidadania regulada" pelo Estado, na medida em que o reconhecimento da cidadania se dá pelo reconhecimento profissional que é, em última instância, regulado pelo Estado. Assim, nessa ordem das coisas, o Estado, através de suas políticas sociais, organiza a sociedade de maneira desigual, definindo, de certa forma, quem é e quem não é cidadão.

Na segunda tradição, o foco dos estudos são o regime político, as instituições e a intermediação de interesses. Nessa perspectiva, a redemocratização do país posta em marcha a partir dos anos 1980 ensejou uma rica bibliografia em relação à reforma do Estado. Como representantes dessa vertente, analisando a questão das "elites burocráticas", Diniz (1997) argumentava que a falta de democracia provoca um insulamento das elites, levando à ausência de accountability, que, por sua vez, tornava difícil a implantação de políticas públicas. Em outras palavras, a autora apontava que a

\footnotetext{
5 Apresentamos os três subconjuntos dos trabalhos propostos por Melo (1999), não necessariamente postos na ordem exata que o autor propõe.
} 
ausência de legitimidade das elites em contextos autocráticos dificultava a implantação de políticas públicas. Bresser-Pereira (2007), na esteira das reformas, vai chamar a atenção para o papel desempenhado pela burocracia pública no Brasil e a forma pela qual ela se relacionou com a principal classe dirigente de cada momento histórico, quer seja para a promoção do desenvolvimento econômico, na qual ela se associa à burguesia industrial, ou na reforma do próprio aparelho do Estado, para torná-lo mais efetivo e mais eficiente.

Ainda nessa primeira tradição, o recorte neoinstitucionalista com Figueiredo e Limongi (1999) vai atentar para o papel das instituições como o Executivo e o Legislativo na nova ordem institucional aberta pela Constituição de 1988. Abranches (1988) chama a atenção para o "presidencialismo de coalizão", sistema em que o Executivo é eleito por partidos distintos daqueles pelos quais são eleitos os parlamentares, obrigando, dessa forma, o governo a construir uma coalizão de partidos a fim de governar e implantar suas políticas.

Na outra ponta, os culturalistas chamam a atenção para a necessidade de uma cultura política cívica para uma melhor implementação de políticas públicas e estabilidade do próprio regime democrático para além das instituições, entre eles Boschi (1999), Baquero (1981) e Moisés (1995). Este artigo insere-se nessa tradição de estudos acadêmicos.

A terceira tradição, mais incipiente do que as demais no país, foi inicialmente capitaneada pela burocracia pública com a produção de trabalhos e estudos relevantes, e tem conseguido uma adesão importante nas últimas décadas nas universidades brasileiras, quer seja com a criação de linhas de pesquisa ou mesmo em centros de pesquisa, Programas de Pós-Graduação em Avaliação de Políticas Públicas em formato profissional, propostos, inclusive, pela Capes.

Colocadas essas diferentes tradições nos estudos de políticas públicas, torna-se importante nos situar no debate interno do segundo grupo, no que se refere à tensão teórica entre o institucionalismo e o culturalismo. Como qualquer conceito, "políticas públicas" é um termo polissêmico que se presta a várias interpretações. Neste artigo, definimos políticas públicas como o conjunto de ações do Estado (no nosso caso, as prefeituras analisadas), desenhadas e implementadas através de programas e de projetos para resolver problemas relacionados a saúde, educação, assistência social, segurança, economia e infraestrutura (Pase e Santos, 2011) ${ }^{6}$. Essas "ações do Estado" podem ser colocadas em prática, grosso modo, "de cima para baixo", pelo arranjo de instituições governamentais. Nesse sentido, as instituições assumem centralidade na elaboração e consecução das políticas públicas ${ }^{7}$. Ou ações "de baixo para cima" na

\footnotetext{
${ }^{6}$ Uma digressão mais completa sobre análise de políticas públicas pode ser encontrada em outro trabalho desenvolvido por nós (Pase e Santos, 2011, vol. 1, p. 69-93).

7 Partimos da concepção de que as políticas públicas podem ser avaliadas objetivamente através dos investimentos públicos feitos pelos governos como também através da avaliação subjetiva da satisfação da
} 
tradição culturalista, as quais nos levam a pensar na importância da sociedade, da cultura política como base para a implementação dessas políticas.

\section{Institucionalismo}

A primazia das instituições em determinar o comportamento de atores, dos governos, da economia e do desenvolvimento econômico é a base teórica sobre a qual a vertente teórica denominada institucionalista se materializa. Sua origem data do século $X X$, nos Estados Unidos. Essa teoria se desdobra em três dimensões diferentes de análise, sendo elas, de acordo com Hall e Taylor (2003), o institucionalismo histórico, o institucionalismo da escolha racional e o institucionalismo sociológico. Para esses autores, os institucionalistas históricos entendem que a organização institucional da comunidade estrutura os comportamentos, estabelece padrões de interação, definindo, portanto, os resultados finais da ação humana. São as regras, normas e convenções oficiais que compõem as instituições na perspectiva dos "históricos". Diferentemente dessa perspectiva, os institucionalistas racionais acreditam em atores políticos que se comportam de maneira utilitária, procurando, através da aplicação da racionalidade e de cálculos estratégicos, maximizar seus ganhos pessoais, levando em conta o comportamento dos outros. Aqui as instituições são os acordos solidários entre atores que compartilham vantagens. A unidade de análise dos históricos diz respeito à estrutura enquanto, para os institucionalistas racionais, é o indivíduo.

Na perspectiva do institucionalismo sociológico, as instituições exercem influência não somente por especificar o que fazer, mas, sobretudo, o que é possível realizar em determinadas circunstâncias. North (2001) entende que o papel das instituições na evolução das sociedades é um fator determinante, demonstrando a influência das instituições no desenvolvimento destas, bem como constatando como o crescimento de longo prazo ou a evolução histórica de uma sociedade são condicionados pela formação e evolução de suas instituições. Assim, o conceito de instituição não se resume às regras e às leis, mas ao "sistema de símbolos", aos "modelos morais" incorporados pelos indivíduos (Hall e Taylor, 2003). Dessa forma, os institucionalistas entendem de maneira restrita as regras formais como as Constituições, as leis, os orçamentos, os contratos, mas, de maneira informal, entendem a ética, a confiança, o empoderamento, a cultura política e outros códigos implícitos. Elinor Ostrom (2000), trazendo uma contribuição singular ao campo institucionalista, concebe as instituições como regras formais e

população em relação a essas políticas, pois, em última análise, são elas que usufruem ou não dessas ações. Aqui, compartilhamos da compreensão de Popkin (1994), da "racionalidade de baixa informação", para quem o cidadão comum pode sim adquirir conhecimento sobre seu entorno, sobre políticas econômicas ou de saúde, mesmo com baixa informação, pois é ele, sobretudo, que vive o cotidiano das cidades, que compra, que vai ao médico, que tem o filho na escola e, portanto, pode emitir uma opinião com base na sua experiência. Assim, a satisfação ou não com uma política pública da população não é uma mera opinião, mas sim um indicador do funcionamento dessas políticas. 
informais que as pessoas reconhecem em dada situação para agir, aquilo que pode ou não ser feito. Para a autora isso pode estar contido tanto na legislação, nos contratos, como nos costumes e valores. A consideração desses fatores informais, entretanto, ocorreria dentro do que os institucionalistas chamam de path trajectory, ou seja, são decorrentes do tipo de instituições que existem num sistema político. Subjacente a essa ideia está a premissa de que o fortalecimento de uma democracia contemporânea seria influenciado, primeiro, pelo conjunto de regras formais e, segundo, pelos aspectos informais e seus mecanismos de execução, que incidem sobre o comportamento dos indivíduos e das organizações de uma sociedade. A inclusão de fatores informais na análise política tornou-se, portanto, necessária em virtude da experiência histórica da maioria dos países na América Latina, a qual tem mostrado que as expectativas geradas pela engenharia institucional estão longe de refletir o que realmente acontece nessas sociedades. Essa perspectiva institucionalista dialoga com a nossa perspectiva culturalista, na medida em que ela incorpora os elementos informais de que nos fala Ostrom (2000). É nesse sentido que buscamos "de baixo para cima" ${ }^{8}$, com a perspectiva culturalista para análise das cidades em tela.

\section{Culturalismo}

Para Putnam (1996), na outra ponta do debate, a política precisa ser analisada "de baixo para cima". Segundo o autor, o importante é investigar quais são as condições culturais indispensáveis para que a democracia responda aos desafios contemporâneos. Tomando como base essa situação, Putnam problematiza por que alguns governos democráticos têm um bom desempenho institucional e outros não. A razão explicativa postulada é que a cultura política e as tradições cívicas, em outras palavras, o capital social, determinaram o desenvolvimento socioeconômico maior da região Norte da Itália em comparação ao da região Sul.

Para Putnam (2000), capital social são práticas sociais, normas e relações de confiança que existem entre cidadãos numa determinada sociedade, bem como sistemas de participação e associação que estimulam a cooperação. Quanto maior e mais rico for o número de possibilidades associativas numa sociedade, maior será o volume de capital social. Dessa forma, esse conceito será mensurado, como veremos na seção seguinte, "A dimensão metodológica e empírica da pesquisa", através de questões que indagam sobre os níveis de confiança interpessoal, bem como a predisposição à participação e cooperação dos cidadãos em cada cidade pesquisada. Aplicando essa perspectiva teórica ao caso do Rio Grande do Sul, Bandeira (2003) estabelece uma diferença regional no

\footnotetext{
${ }^{8}$ Não é objetivo deste artigo discutir as diferenças em profundidade entre as diferentes concepções teóricas do neoinstitucionalismo; nosso propósito é tão somente demarcar o debate para, na sequência, dialogarmos com as posições teóricas do culturalismo. Certamente, North (2001) é um dos grandes representantes teóricos desse neoinstitucionalismo americano na contemporaneidade.
} 
Estado muito semelhante ao que Putnam (2000) fez na Itália. Como uma primeira aproximação, haveria uma diferença entre o "Norte colonial", cuja matriz é de imigrantes alemães e italianos com existência de pouca escravidão e predomínio do minifúndio, e o "Sul", uma matriz ibérica com o predomínio do latifúndio e o uso extensivo da mão de obra escrava.

No que se refere à primeira região, Bandeira (2003) ressalta que essas zonas coloniais de imigração alemã e italiana estão dotadas de mais capital social do que as da região sul. Nas primeiras, encontramos uma infinidade de associações recreativas, clubes sociais, sociedades de canto, de atiradores e artísticas, bem como uma intensa vida social colaborativa e cooperativa entre os primeiros colonos que aqui chegaram no século XIX. Nos municípios que surgiram a partir do desmembramento de São Leopoldo, já assinalados por nós na parte histórica, vê-se um quadro de povoamento semelhante, no qual a composição étnica esteve inicialmente marcada pelos alemães (Weber, 2006), como no caso das cidades aqui analisadas, Novo Hamburgo e Estância Velha. Todavia, deve-se levar em consideração que outros grupos étnicos raciais também compuseram o cenário dessa região, especialmente índios, negros, açorianos e luso-brasileiros, muito embora apareçam comumente na bibliografia como agentes de experiências fracassadas (Nunes, 2009). Os dados de nossa pesquisa em 2012 desmistificaram a ideia de "sociedade alemã" atualmente nessas localidades, na medida em que apenas $31 \%$ dos hamburgueses se declararam alemães e, em Estância Velha, esse percentual ficou em $37 \%$, ligeiramente maior, mas não preponderante.

Outro estudo que analisa o capital social no Rio Grande do Sul do ponto de vista da qualidade das administrações municipais e da governança, ou seja, quanto à transparência na formulação e à eficácia de políticas públicas, é o de Monasterio (2003). Nas localidades que ele denomina de planalto e serra (utilizando outra divisão territorial, mas referindo-se às zonas de colonização) aparecem (ou apresentam-se) os melhores indicadores de qualidade da administração pública em contraposição às regiões da campanha (Sul). Em sua análise, na região da campanha, há menor formulação legislativa, menor informatização, menos conselhos, gasta-se o mínimo previsto na legislação com saúde e educação, ao passo que, na serra e no planalto, esses indicadores tendem a ser melhores, na perspectiva do autor, pela presença de capital social.

Em outro trabalho, comparando as cidades de Caxias do Sul e Pelotas, verificamos que o Sistema Único de Saúde Odontológico, implantado em ambas as cidades, mostrou um melhor desempenho em Caxias do Sul do que em Pelotas, cidade esta detentora de menor capital social do que Caxias do Sul (Santos, 2013).

A primazia da cultura política, portanto, da importância do capital social, para explicar o desempenho institucional de uma região, conforme Putnam (2000), Bandeira (2003), Monasterio (2003) e Santos (2013), constitui-se em importante variável para 
compreender o desenvolvimento econômico e o desempenho das políticas públicas, como as que são analisadas neste artigo.

Isso não significa que as instituições não tenham uma importância fundamental para o desenvolvimento e para o próprio desempenho dos governos e de suas políticas. Dito isso, deparamo-nos com a dificuldade de estabelecermos a "estrutura causal" sobre o desempenho dos governos. Seria a variável instituições ou a variável cultura política que determina o desempenho satisfatório dos governos? A solução para a dicotomia de quem veio primeiro parece não contribuir efetivamente para a solução do problema da eficiência das organizações.

$\mathrm{Na}$ encruzilhada da teoria culturalista e institucional (formal versus informal), o Banco Mundial tem proposto uma abordagem sinérgica, partindo do princípio de que instituições formais necessitam do envolvimento e do compromisso social a fim de que não se tornem instituições vazias e inúteis (Baquero, 2013). Essa abordagem possibilita uma combinação de fatores culturais, pois leva em conta as condições de reciprocidade e confiança dentro de um sistema político, ou seja, o capital social com elementos institucionais tais como orçamentos públicos, cumprimento de contratos, garantia de liberdades civis e políticas. Em síntese, o Banco Mundial reconhece que a vitalidade das relações sociais é tão importante quanto a moldura institucional de um sistema político (Baquero, 2013). A partir do exposto e no intuito de avaliar o impacto das determinações do capital social sobre as políticas públicas nas cidades de Novo Hamburgo e Estância Velha, começamos pela análise das dotações orçamentárias nessas cidades, o grau de satisfação de seus usuários em relação aos serviços básicos prestados pelo município, bem como as dotações de capital social. Por fim, a correlação existente entre capital social e satisfação dos munícipes com suas políticas públicas é analisada.

\section{A dimensão metodológica e empírica da pesquisa}

\section{Dimensão metodológica}

A metodologia utiliza os resultados de duas pesquisas quantitativas, tipo surveys domiciliares, com amostras probabilísticas por conglomerado, compostas de 613 questionários aplicados em Novo Hamburgo e 606 em Estância Velha, ambas com erro amostral de $4 \%$ e confiança de $95 \%$, sendo divididos por bairros e quadras, entre janeiro de 2012 a junho de 2013, aplicadas pelo Centro de Pesquisa e Planejamento da Universidade Feevale (CPP/Feevale) em parceria com o Núcleo de Pesquisa sobre América Latina da UFRGS (Nupesal). Com base no mapa da cidade delimitaram-se os bairros e as quadras, seguido de um sorteio aleatório simples das quadras dentro de cada bairro. No momento da coleta em cada quadra sorteada, foi realizada uma amostragem sistemática dos domicílios, obedecendo ao critério do número de domicílios a serem avaliados em 
cada quadra. A coleta de dados foi realizada através de questionário-padrão com 40 questões entre abertas e fechadas (Nupesal), somente nos domicílios do município, com pessoas de 16 anos de idade ou mais (por serem consideradas eleitores), por equipe de entrevistadores. Esta pesquisa é resultado do projeto de pesquisa "Capital social e políticas públicas em Novo Hamburgo e Estância Velha", em desenvolvimento no período 2012-2015.

Também foi utilizada pesquisa documental ao site das referidas prefeituras, IBGE, TCE (Tribunal de Contas do Estado do Rio Grande do Sul) e da FEE (Fundação de Economia e Estatística do Rio Grande do Sul). Os dados coletados foram analisados no programa estatístico SPSS com o auxílio dos testes Kruskal-Wallis e Mann-Whitney. Esses testes são utilizados largamente na análise estatística, precisamente quando a variável está em escala ordinal, como é o nosso caso; o teste mostrou-se muito eficiente como veremos.

Dimensão empírica

Gastos e satisfação com os serviços públicos

Numa perspectiva institucional, o orçamento dos municípios constitui-se em importante variável das políticas públicas, as quais impactam positivamente sobre a satisfação dos cidadãos. Todavia, é preciso fazer a ressalva inicial de que o orçamento de Novo Hamburgo é seis vezes maior do que o de Estância Velha. Muito embora a quantia dos gastos totais seja discrepante entre as cidades, devido a suas receitas e populações diferentes, observamos que os dois principais gastos em ambas as cidades estão relacionados com educação e saúde. Esse fato ocorre porque, conforme o artigo 212 da Constituição Federal, os municípios devem aplicar anualmente "vinte e cinco por cento, no mínimo, da receita resultante de impostos, compreendida a proveniente de transferências, na manutenção e desenvolvimento do ensino".

De acordo com a Emenda Constitucional 29, de 13 de setembro de 2000, os municípios devem aplicar $15 \%$ do produto da arrecadação dos impostos, como forma de garantir os recursos mínimos destinados a essa área. Assim, a saúde vem em segundo lugar nos gastos nas cidades, depois da educação. Destacamos que se trata de recursos mínimos, não impedindo os Executivos de destinarem percentuais superiores nas leis orçamentárias. Essa deliberação também se estende para os gastos com educação.

De qualquer forma, para dar uma pista nessa direção e no intuito de disponibilizar maior inteligibilidade a esses dados, dividimos os gastos totais pelo número de habitantes de cada cidade, para podermos visualizar o quanto cada cidade investiu em seus habitantes nas diferentes áreas no ano de 2012, cotejando com os dados disponíveis de nossa pesquisa de opinião em 2012. 
Observando-se a Tabela 1, notamos que a educação, como área de maior investimento de ambos, R\$525,93 por habitante em Novo Hamburgo e R\$ 595,11 em Estância Velha, foi a área mais bem avaliada, com $48 \%$ e $56 \%$ de bom e ótimo, respectivamente, depois de obras, com 55\% em Novo Hamburgo e $75 \%$ em Estância Velha:

Tabela 1

Avaliação de satisfação com as políticas públicas dos municípios de Novo Hamburgo e Estância Velha e gastos por habitante - 2012

\begin{tabular}{|l|c|c|c|c|}
\hline \multirow{2}{*}{ Área } & \multicolumn{2}{|c|}{ Novo Hamburgo } & \multicolumn{2}{c|}{ Estância Velha } \\
\cline { 2 - 5 } & Per capita (R\$) & $\begin{array}{c}\text { Avaliação bom e } \\
\text { ótimo (\%) }\end{array}$ & Per capita (R\$) & $\begin{array}{c}\text { Avaliação bom } \\
\text { e ótimo (\%) }\end{array}$ \\
\hline Educação & 525,93 & 48 & 595,11 & 56 \\
\hline Saúde & 497,15 & 20 & 456,36 & 32 \\
\hline Obras $^{1}$ & 141,76 & 55 & 180,52 & 75 \\
\hline Segurança & 69,86 & 26 & 47,88 & 52 \\
\hline $\begin{array}{l}\text { Esporte/ lazer/ } \\
\text { cultura }\end{array}$ & 34,52 & 33 & 14,51 & 44 \\
\hline Gasto total & $1.269,25$ & 182 & $1.294,40$ & 259 \\
\hline $\begin{array}{l}\text { Número de } \\
\text { habitantes }\end{array}$ & \multicolumn{2}{|c|}{240.376} & & 43.646 \\
\hline
\end{tabular}

Fonte: Elaboração própria com base no projeto de pesquisa "Capital social e políticas públicas em Novo Hamburgo e Estância Velha: subsídios para o desenvolvimento", ligado ao Grupo de Pesquisa em Desenvolvimento Regional (CPP/Feevale); ano: 2012.

Questão: "Como você avalia a qualidade dos serviços públicos em sua cidade nas áreas de saúde, educação etc.: Péssimo, Ruim, Regular, Bom e Ótimo?".

1 Incluímos saneamento e habitação como "área Obras" nesta tabela, pois no questionário original trabalhamos com perguntas separadas.

De acordo com a Tabela 1, de fato as três áreas que mais receberam recursos per capita nos dois municípios foram as mais bem avaliadas, com exceção da saúde, que, embora tenha recebido aportes na monta de R\$ 497,15 por pessoa em Novo Hamburgo, teve apenas $20 \%$ de Bom ou Ótimo na avaliação. E também em Estância Velha, onde foram aplicados $R \$ 456,36$, mas apenas $32 \%$ da população avaliou a saúde como Bom ou Ótimo. O problema da saúde parece ser a questão central em ambas as cidades.

No caso de Estância Velha, a cidade investiu mais em educação e obras (per capita) na comparação com Novo Hamburgo, o que parece se refletir nas avaliações positivas na Tabela 1, com 56\% de Bom e Ótimo em educação e $75 \%$ em obras. Com exceção da saúde, com a avaliação mais baixa em Estância Velha, 32\%, as demais áreas receberam escores acima de $40 \%$. No caso da segurança, com $44 \%$ de Bom ou Ótimo, a 
avaliação também reflete o fato de a cidade ser de pequeno porte e estar situada mais afastada do centro da região metropolitana.

Em Novo Hamburgo, ainda na Tabela 1, investiu-se mais em saúde e segurança em comparação com Estância Velha, apesar disso não ocorreu o mesmo fenômeno de uma avaliação positiva como em sua cidade vizinha. Na saúde, apenas $20 \%$ de Bom e Ótimo e na segurança $26 \%$, como já assinalamos ${ }^{9}$.

No caso de Estância Velha, a exemplo de cidades de menor porte, fatores como capacidade industrial reduzida, relacionamento das pessoas entre si e seus relacionamentos comunitários (confiança interpessoal) parecem ter um efeito positivo na prevenção da criminalidade. Nem mesmo os percentuais baixos de investimento em segurança $(R \$ 47,88)$ chegam a afetar significativamente a cidade ${ }^{10}$. Entretanto, em Novo Hamburgo, que é considerada uma cidade industrializada, populosa e com laços comunitários mais "frouxos", o índice de satisfação com segurança é mais baixo, o que revela uma preocupação dos cidadãos com a criminalidade, que é mais significativa. Isso ocorreu apesar de os investimentos em segurança em Novo Hamburgo ( $R \$ 69,86$ ) serem maiores do que em Estância Velha. Tal situação corrobora os resultados da pesquisa de Putnam na Itália, que constataram que a urbanização pode se mostrar deletéria para a formação do capital social sob certas condições (Putnam, 1996).

Essas avaliações proporcionam subsídios teórico-práticos importantes para compreender o impacto direto desses investimentos na qualidade de vida e bem-estar das pessoas. Pesquisas subsequentes que desenvolvam essa dimensão institucional poderão nos permitir estabelecer comparações em termos longitudinais muito mais precisas. Nosso intuito inicial aqui é apenas sublinhar um certo impacto que os gastos têm sobre a satisfação dos cidadãos.

Os dados evidenciam a importância do volume de investimentos em si e dos previstos em lei, que, aplicados de igual forma em dimensões materiais essenciais para a qualidade de vida das pessoas, produziram resultados, alguns iguais, outros diferentes, dadas as características particulares de cada cidade, como veremos.

Nesse contexto, os dados da pesquisa revelam que em Estância Velha, apesar de seu orçamento menor, a população recebeu investimentos per capita muito semelhantes aos de Novo Hamburgo e, em algumas áreas como educação e obras, até maiores. Igualmente Estância Velha manifestou maior satisfação com as instituições prestadoras de serviço do que Novo Hamburgo. O número menor de habitantes somado ao investimento per capita em Estância Velha parece explicar em parte esse fenômeno. Contudo, ainda permanece outra questão: é o investimento público a única variável que explica os níveis de satisfação com os serviços prestados pelo Estado nessas cidades? Se

\footnotetext{
9 Se dispuséssemos de pesquisas de opinião longitudinais ano a ano poderíamos responder mais precisamente se esse percentual de avaliação negativa em 2012 está aumentando ou diminuindo.

10 É importante lembrar que é do estado e não dos municípios ou regiões a responsabilidade com a segurança. Entretanto, os municípios têm cada vez mais discutido sobre sua participação nessa área.
} 
a dotação orçamentária ajuda na compreensão de parte desse fenômeno, por outro lado, não ajuda a explicar por que a saúde, com a segunda dotação per capita nas cidades, obteve o último lugar na satisfação da população. Tal dúvida também se aplica à questão da segurança pública.

A esse respeito é importante salientar que o município não tem uma responsabilização direta pela questão da segurança, portanto, a relação entre investimentos nessa área e satisfação precisa ser relativizada. Todavia, procurando evitar a monocausalidade, pensamos que, para além do investimento dos respectivos orçamentos nas regiões, a qualidade do tecido social em que eles são aplicados pode ajudar a explicar os níveis de satisfação dessas populações, ou seja, a avaliação do desempenho dos serviços públicos prestados tanto em Novo Hamburgo como em Estância Velha. Nessa perspectiva, pensamos que os níveis de capital social existentes nessas cidades possibilitariam um melhor funcionamento das instituições prestadoras de serviços públicos.

\section{Capital social e políticas públicas}

Para avaliar a relação entre o capital social e as políticas públicas, examinamos os níveis de capital social nos municípios estudados, em termos de confiança interpessoal, solidariedade, organização e participação política e sua relação com o funcionamento das políticas públicas. Nesse sentido, o índice que criamos procura contemplar as diferentes dimensões que envolvem o conceito de capital social.

Na Tabela 2, podemos observar que os índices de capital social na cidade de Novo Hamburgo apresentam $1 \%$ de alto, $28 \%$ de médio e $71 \%$ de baixo, comparados com $2 \%$ de alto, $40 \%$ de médio, caindo para $58 \%$ de baixo em Estância Velha. Numa análise comparativa, a cidade de Estância Velha mostra maiores estoques de capital social entre seus habitantes em comparação a Novo Hamburgo: 
Tabela 2

Í ndice de capital social (ICS) dos municípios de Novo Hamburgo e Estância Velha ${ }^{11}$ (\%)

\begin{tabular}{|l|c|c|}
\hline & Novo Hamburgo & Estância Velha \\
\hline Alto & 1 & 2 \\
\hline Médio & 28 & 40 \\
\hline Baixo & 71 & 58 \\
\hline Total & 100 & 100 \\
\hline
\end{tabular}

Fonte: Elaboração própria com base no projeto de pesquisa

"Capital social e políticas públicas em Novo Hamburgo e Estância

Velha: subsídios para o desenvolvimento" (CPP/Feevale); ano:

2012; Novo Hamburgo N: 613; Estância Velha N: 606.

Para melhor exemplificarmos o índice de capital social e a título de ilustração das questões que compõem esse índice, na Tabela 3, utilizamos a confiança interpessoal, como uma das tantas questões que mensuram o capital social. Os dados mostram que 24\% das pessoas em Novo Hamburgo responderam que "se pode confiar nas pessoas", contra $20 \%$ de Estância Velha, revelando haver uma proximidade no que se refere à confiança encapsulada, ou seja, intracomunitária:

\footnotetext{
${ }^{11} \mathrm{O}$ índice de capital social (ICS) foi construído em parceria com o Nupesal de forma idêntica para as duas cidades a partir da seleção de nove questões que fossem capazes de dar conta do conceito de capital social em suas diferentes dimensões, conforme Robert Putnam. Nesse sentido, procuramos açambarcar a dimensão da confiança interpessoal de uma determinada sociedade, a dimensão atitudinal em relação à solidariedade entre seus cidadãos e a dimensão societal que atenta para os níveis de organização e participação de uma determinada comunidade. No nosso caso, o indicador é quantitativo e se baseia num processo de contagem, e este tem como finalidade agregar respostas com o objetivo de avaliar, classificar e identificar relações e variações das respostas dado nosso objeto de estudo. São elas: "Em termos gerais, o senhor diria que se pode confiar nas pessoas ou não se pode confiar nas pessoas?": Sim (peso 2), Não (peso 0); "Gostaria de saber se o senhor confia muito (peso 2), pouco (peso 1) ou não confia (peso 0 ) na: igreja, família, vizinhos, associações comunitárias, sindicatos"; "O senhor costuma participar de: partidos políticos, reuniões políticas, comícios, associações comunitárias, associações religiosas, associações sindicais, conselhos populares, ONGs, orçamento participativo, abaixo-assinados, manifestações ou protestos, greves, ocupação de terrenos ou prédios públicos, outros?": Sim (peso 2), Não (peso 0); "Nos últimos anos, o senhor tentou resolver algum problema local do bairro/comunidade junto com outras pessoas?": Sim (peso 2), Não (peso 0); "Dentre os grupos que eu vou mencionar, quais deles existem no seu bairro: grupo político, grupo ou associação cultural, grupo educacional, grupo esportivo, grupo de jovens, ONG ou grupo cívico, grupo baseado na comunidade étnica, grupo de mulheres, outro?": Sim (peso 2), Não (peso 0); "Atualmente o senhor participa de algum grupo ou organização?": Sim (peso 2), Não (peso 0); "Se precisasse viajar por um ou dois dias, o senhor poderia contar com vizinhos para cuidar da sua casa e/ou filhos?": Sim (peso 2), Provavelmente (peso 1), Não (peso 0); "Em uma situação de emergência como a doença de um familiar ou perda de emprego, o senhor receberia ajuda?": familiares ( peso 0), vizinhos (peso 2), colegas de trabalho (peso 2); "Se um projeto da comunidade não Ihe beneficia diretamente, mas pode beneficiar outras pessoas do seu bairro, o senhor contribui para esse projeto?": Sim (peso 2), Não (peso 0). Esse índice está ancorado teoricamente no conceito de capital social de Putnam (2000), para quem relações de confiança interpessoais são indicadores da existência de capital social em uma sociedade.
} 
Tabela 3

Confiança interpessoal ( \%)

\begin{tabular}{|l|c|c|}
\hline & Novo Hamburgo & Estância Velha \\
\hline $\begin{array}{l}\text { Não se pode } \\
\text { Confiar nas pessoas }\end{array}$ & 69 & 77 \\
\hline $\begin{array}{l}\text { Pode-se } \\
\text { confiar nas pessoas }\end{array}$ & 24 & 20 \\
\hline Não sabe & 7 & 3 \\
\hline Total & 100 & 100 \\
\hline
\end{tabular}

Fonte: Elaboração própria com base no projeto de pesquisa "Capital social e políticas públicas em Novo Hamburgo e Estância Velha: subsídios para o desenvolvimento" (CPP/Feevale); ano: 2012; Novo Hamburgo N: 613; Estância Velha N: 606.

Questão: "Em termos gerais, você diria que: 1) se pode confiar nas pessoas; 2) não se pode confiar nas pessoas; 3) NS".

Na mesma dimensão da confiança interpessoal, indagamos os entrevistados: "Se precisasse viajar por um ou dois dias, você poderia contar com a ajuda de vizinhos para cuidar de sua casa e/ou dos seus filhos?". Os resultados apresentados na Tabela 4 mostram que, em Novo Hamburgo, 77\% responderam afirmativamente que "sim" ou "provavelmente" e 17\%, negativamente. Em Estância Velha, o percentual dos que responderam "sim" ou "provavelmente" sobe para $85 \%$, e $12 \%$ disseram que não poderiam:

Tabela 4

Contar com a ajuda de vizinhos (\%)

\begin{tabular}{|l|c|c|}
\hline & Novo Hamburgo & Estância Velha \\
\hline Sim & 66 & 78 \\
\hline Provavelmente & 11 & 7 \\
\hline Não & 17 & 12 \\
\hline Não Sabe & 5 & 2 \\
\hline Total & 100 & 100 \\
\hline
\end{tabular}

Fonte: Elaboração própria com base no projeto de pesquisa "Capital social e políticas públicas em Novo Hamburgo e Estância Velha: subsídios para o desenvolvimento" (CPP/Feevale); ano: 2012; Novo Hamburgo N: 613; Estância Velha N: 606.

Questão: "Se precisasse viajar por um ou dois dias, você poderia contar com a ajuda de vizinhos para cuidar da sua casa e/ou dos filhos?: 1) Sim; 2) Provavelmente; 3) Não; 4) NS".

Tais resultados sugerem existir nessas duas cidades níveis elevados de capital social comunitário, ingredientes necessários para construir uma cultura política participativa. Essa expectativa confirma-se nos dados da Tabela 5, quando perguntamos aos entrevistados sobre a importância da participação das pessoas em projetos comunitários. 
$\mathrm{Na}$ Tabela 5, como podemos observar, $90 \%$ da população de Estância Velha respondeu que, mesmo que um projeto da comunidade não the beneficie, mas possa beneficiar outras pessoas do seu bairro, ele contribuiria para o projeto, e apenas $5 \%$ não contribuiriam. A mesma pergunta recebeu um percentual menor em Novo Hamburgo, $78 \%$ contribuiriam e $9 \%$ não contribuiriam. Os resultados parecem indicar que a cidade de Estância Velha tem maior potencial de produzir capital social do que Novo Hamburgo. Também podemos salientar que o tamanho da cidade tem influência sobre os estoques de capital social, quanto menor a cidade, maior parece ser o capital social, como já assinalamos ${ }^{12}$ :

\section{Tabela 5}

Projeto da comunidade que beneficia outras pessoas (\%)

\begin{tabular}{|l|c|c|}
\hline & Novo Hamburgo & Estância Velha \\
\hline Sim & 78 & 90 \\
\hline Não & 9 & 5 \\
\hline Não Sabe & 13 & 5 \\
\hline Total & 100 & 100 \\
\hline
\end{tabular}

Fonte: Elaboração própria com base no projeto de pesquisa "Capital social e políticas públicas em Novo Hamburgo e Estância Velha: subsídios para o desenvolvimento" (CPP/Feevale; ano: 2012; Novo Hamburgo N: 613; Estância Velha N: 606.

Questão: "Se um projeto da comunidade não lhe beneficia diretamente, mas pode beneficiar outras pessoas do seu bairro, você contribuiria para este projeto?: 1) Sim; 2) Não; 3) NS".

A existência de estoques mais elevados de capital social em Estância Velha comparados com Novo Hamburgo suscitou a necessidade de analisar o impacto desse capital social sobre as políticas municipais. Nesse sentido, identificamos não somente uma maior confiança interpessoal, como também uma maior participação da população de Estância Velha em associações comunitárias, grupos esportivos, clubes etc. De maneira geral, quando os entrevistados responderam sobre a qualidade dos serviços públicos em sua cidade, $26 \%$ em Novo Hamburgo avaliaram como Ótimo ou Bom, contra 27\% como Ruim ou Péssimo, conforme Tabela 6:

\footnotetext{
${ }^{12}$ Nas duas cidades de médio porte em que aplicamos nossas pesquisas, obtemos em Novo Hamburgo $1 \%$ de capital social alto e em São Leopoldo 0\%, ao passo que em Estância Velha, cidade de pequeno porte, encontramos $2 \%$ de capital social alto. Na sequência de nossas pesquisas estará a cidade vizinha, Estância Velha, que também é de pequeno porte, e deve apresentar estoques de capital social alto também.
} 
Tabela 6

Avaliação geral da qualidade dos serviços públicos em sua cidade (\%)

\begin{tabular}{|l|c|c|}
\hline & Novo Hamburgo & Estância Velha \\
\hline Ótimo & 2 & 3 \\
\hline Bom & 24 & 34 \\
\hline Regular & 44 & 39 \\
\hline Ruim & 14 & 13 \\
\hline Péssimo & 13 & 8 \\
\hline Sem condições de opinar & 2 & 3 \\
\hline Total & 100 & 100 \\
\hline
\end{tabular}

Fonte: Elaboração própria com base no projeto de pesquisa "Capital social e políticas públicas em Novo Hamburgo e Estância Velha: subsídios para o desenvolvimento" (CPP/Feevale); ano: 2012; Novo Hamburgo N: 613; Estância Velha N: 606.

Questão: "Agora, de maneira geral, como você avalia a qualidade dos serviços públicos em sua cidade?: Péssimo, Ruim, Regular, Bom e Ótimo, NS".

Poderíamos, então, perguntar: o que está proporcionando esse "equilíbrio" entre as avaliações positivas e negativas? Os $27 \%$ do polo negativo em Novo Hamburgo poderiam ser explicados em parte pela avaliação negativa na área da saúde, da segurança e de certa forma do esporte/lazer/cultura na cidade, conforme a Tabela 7. Com a exceção deste último, esporte/lazer/cultura, que teve um percentual de $27 \%$ dos entrevistados que avaliaram como Ruim ou Péssimo, ficando abaixo da avaliação positiva de $33 \%$ de Bom e Ótimo, tanto a saúde, com mais da metade dos entrevistados avaliando em Ruim ou Péssimo, 56\%, quanto a segurança, com 47\% de Ruim ou Péssimo, ambas superaram as avaliações positivas. Essas áreas reforçam as avaliações negativas dos serviços públicos já observados na Tabela 6. Por exemplo, quando os entrevistados foram solicitados a apontar qual era o maior problema do município, cerca de $40 \%$ deles responderam ser a saúde e $28 \%$ indicaram a segurança pública, reforçando esses dois itens como um problema público.

Por outro lado, a avaliação Bom ou Ótimo para habitação (56\%), saneamento $(55 \%)$, transporte $(53 \%)$ e educação $(48 \%)$ contribuiu na média com o polo positivo de $26 \%$, conforme Tabela 7: 
Tabela 7

Qualidade dos serviços públicos em Novo Hamburgo por área (\%)

\begin{tabular}{|l|c|c|c|c|c|c|c|}
\hline & Péssimo & Ruim & Regular & Bom & Ótimo & NS & Total \\
\hline Saúde & 36 & 20 & 21 & 18 & 2 & 4 & 100 \\
\hline Segurança pública & 26 & 21 & 26 & 24 & 2 & 1 & 100 \\
\hline Esporte/ Lazer/ Cultura & 12 & 15 & 25 & 31 & 2 & 15 & 100 \\
\hline Obras/ Saneamento básico & 6 & 8 & 26 & 51 & 4 & 4 & 100 \\
\hline Transporte & 5 & 11 & 18 & 49 & 4 & 13 & 100 \\
\hline Educação & 3 & 5 & 31 & 44 & 4 & 14 & 100 \\
\hline Habitação & 3 & 7 & 31 & 52 & 4 & 3 & 100 \\
\hline
\end{tabular}

Fonte: Elaboração própria com base no projeto de pesquisa "Capital social e políticas públicas em Novo Hamburgo e Estância Velha: subsídios para o desenvolvimento" (CPP/Feevale); ano: 2012; N: 613.

Questão: "Como você avalia a qualidade dos serviços públicos em sua cidade nas áreas de saúde, educação etc.?: Péssimo, Ruim, Regular, Bom e Ótimo, NS".

Na cidade de Estância Velha, o percentual de Ótimo e Bom na avaliação dos serviços públicos subiu para $37 \%$, cerca de 10 pontos percentuais a mais do que em Novo Hamburgo; o de Ruim e Péssimo caiu para 21\%, conforme Tabela 6 . O que poderia explicar essa "assimetria positiva" em Estância Velha? O saneamento básico com $79 \%$ de Bom ou Ótimo, a habitação com $71 \%$ e a educação com $56 \%$ foram as políticas públicas mais bem avaliadas e que mais contrastaram com o polo negativo, contribuindo assim para o resultado positivo da pesquisa, conforme a Tabela 8. De todas as variáveis analisadas, a única que obteve um resultado negativo mais expressivo foi a saúde pública, com 37\% de Péssimo e Ruim, igualmente em Novo Hamburgo, 56\%, muito embora esse último em percentual mais expressivo.

Desse modo, os $21 \%$ do polo negativo, já mencionados, possivelmente foram puxados pela avaliação negativa que os entrevistados fizeram da saúde, sendo esta a única variável em que o polo negativo superou o polo positivo. Também o transporte, muito embora com $44 \%$ de avaliação positiva (bom e ótimo), foi a segunda área mais mal avaliada, com $24 \%$ negativo (ruim e péssimo), seguido da segurança pública, em terceiro lugar, com $19 \%$ de avaliações negativas. 
Tabela 8

Qualidade dos serviços públicos em Estância Velha por área (\%)

\begin{tabular}{|l|c|c|c|c|c|c|c|}
\hline & Péssimo & Ruim & Regular & Bom & Ótimo & NS & Total \\
\hline Saúde & 22 & 15 & 27 & 30 & 2 & 4 & 100 \\
\hline Segurança pública & 8 & 11 & 28 & 48 & 3 & 1 & 100 \\
\hline Esporte/ Lazer/ Cultura & 6 & 8 & 26 & 41 & 3 & 16 & 100 \\
\hline Saneamento básico & 2 & 4 & 11 & 75 & 4 & 4 & 100 \\
\hline Transporte & 11 & 13 & 19 & 42 & 2 & 12 & 100 \\
\hline Educação & 2 & 4 & 21 & 48 & 8 & 17 & 100 \\
\hline Habitação & 3 & 6 & 16 & 66 & 5 & 2 & 100 \\
\hline
\end{tabular}

Fonte: Elaboração própria com base no projeto de pesquisa "Capital social e políticas públicas em Novo Hamburgo e Estância Velha: subsídios para o desenvolvimento" (CPP/Feevale); ano: 2012; N: 606.

Questão: "Como você avalia a qualidade dos serviços públicos em sua cidade nas áreas de saúde, educação etc. ?: Péssimo, Ruim, Regular, Bom e Ótimo, NS".

A partir desse conjunto de dados arrolados das duas cidades, e perseguindo nossa hipótese central de que o capital social poderia estar impactando positivamente sobre as políticas públicas, foi necessário verificar se de fato existe uma relação entre o capital social e a satisfação com os serviços públicos de maneira geral. Assim, tornou-se necessário cruzarmos o índice de capital social que açambarca de forma mais apropriada o conceito de capital social, que está para além da dimensão meramente da confiança interpessoal (mas também inclui a dimensão da solidariedade e participação), com as variáveis de satisfação em relação aos serviços públicos. Nesse sentido, utilizamos dois testes não paramétricos, o teste Kruskal-Wallis e o teste Mann-Whitney, para avaliarmos se existem diferenças significativas na satisfação dos serviços públicos quando comparamos os três níveis do indicador de capital social e, desse modo, comprovarmos nossa hipótese de trabalho. A escolha do Kruskal-Wallis e o teste Mann-Whitney justificase pelo fato de estarmos comparando/relacionando variáveis em escala ordinal (Levin, Fox e Forde, 2012).

Como podemos observar no Quadro 1, na variável saúde, quando aumentam os indicadores de capital social, 1 (baixo), 2 (médio) e 3 (alto), também aumentam os escores de satisfação, de 290,69 no nível 1 para 307,73 no nível 2, caindo para 235,00 no nível 3. Na educação também se repete o mesmo fenômeno. Quando aumentam os escores de capital social de 1 para 2, temos 256,99 para 284,46 e, no nível 3, o escore fica em 263,60. Todavia, quando observamos a área de esporte, lazer e cultura, há certa linearidade, à medida que aumentam os indicadores de capital social 1, 2 e 3, aumentam os escores respectivamente para $252,64,282,23$ e 295,90. O mesmo vai ocorrer com o transporte e a segurança pública: 
Quadro 1

Teste Kruskal-Wallis para comparação da satisfação dos serviços públicos entre os níveis do indicador de capital social (Novo Hamburgo)

\begin{tabular}{|c|c|c|c|c|c|}
\hline & I NDCOD & $\mathbf{N}$ & Mean Rank & Chi-Square & P-Value \\
\hline \multirow{4}{*}{ Saúde } & Baixo & 419 & 290,69 & \multirow{4}{*}{1,944} & \multirow{4}{*}{0,378} \\
\hline & Médio & 165 & 307,73 & & \\
\hline & Alto & 5 & 235,90 & & \\
\hline & Total & 589 & & & \\
\hline \multirow{4}{*}{ Educação } & Baixo & 371 & 256,99 & \multirow{4}{*}{4,219} & \multirow{4}{*}{0,121} \\
\hline & Médio & 153 & 284,46 & & \\
\hline & Alto & 5 & 263,60 & & \\
\hline & Total & 529 & & & \\
\hline \multirow{4}{*}{ Esporte/ Lazer/ Cultura } & Baixo & 368 & 252,64 & \multirow{4}{*}{4,726} & \multirow{4}{*}{0,094} \\
\hline & Médio & 149 & 282,23 & & \\
\hline & Alto & 5 & 295,9 & & \\
\hline & Total & 522 & & & \\
\hline \multirow{4}{*}{ Transporte } & Baixo & 374 & 261,14 & \multirow{4}{*}{4,482} & \multirow{4}{*}{0,106} \\
\hline & Médio & 156 & 281,57 & & \\
\hline & Alto & 5 & 358 & & \\
\hline & Total & 535 & & & \\
\hline \multirow{4}{*}{ Segurança } & Baixo & 436 & 300,05 & \multirow{4}{*}{5,109} & \multirow{4}{*}{0,078} \\
\hline & Médio & 168 & 313,1 & & \\
\hline & Alto & 5 & 464,3 & & \\
\hline & Total & 609 & & & \\
\hline \multirow{4}{*}{ Saneamento } & Baixo & 420 & 293,36 & \multirow{4}{*}{0,08} & \multirow{4}{*}{0,961} \\
\hline & Médio & 163 & 297,38 & & \\
\hline & Alto & 5 & 296,2 & & \\
\hline & Total & 588 & & & \\
\hline \multirow{4}{*}{ Habitação } & Baixo & 425 & 296,03 & \multirow{4}{*}{0,26} & \multirow{4}{*}{0,878} \\
\hline & Médio & 162 & 298,74 & & \\
\hline & Alto & 5 & 263,9 & & \\
\hline & Total & 592 & & & \\
\hline
\end{tabular}

Fonte: Elaboração própria com base no projeto de pesquisa "Capital social e políticas públicas em Novo Hamburgo e Estância Velha: subsídios para o desenvolvimento" (CPP/Feevale); ano: 2012.

Essas evidências nos levaram a aplicar o teste de Kruskal-Wallis para verificarmos se havia significância entre as variáveis cruzadas. Nesses dois últimos casos (transporte e segurança pública), os valores do p-value ficaram muito próximos da significância estatística, como podemos notar, 0,078 na segurança pública e 0,094 no esporte, lazer e cultura. Muito embora esse teste tenha nos aproximado de nossa hipótese de trabalho, o número baixo de $\mathrm{N}=5$ nos levou a agrupar esses casos do nível 3 com o nível 2, que apresentam capital médio no teste do Quadro 2: 
Quadro 2

Teste Mann-Whitney para comparação da satisfação dos serviços públicos entre os níveis agrupados do indicador de capital social (Novo Hamburgo)

\begin{tabular}{|c|c|c|c|c|c|c|}
\hline & I NDMODI F & $\mathbf{N}$ & $\begin{array}{l}\text { Mean } \\
\text { Rank }\end{array}$ & $\begin{array}{l}\text { Sum of } \\
\text { Ranks }\end{array}$ & Mann-Whitney U & P-value \\
\hline \multirow{3}{*}{ Saúde } & 1 & 419 & 290,69 & 121799,5 & \multirow{3}{*}{33809,500} & \multirow{3}{*}{0,315} \\
\hline & 2 & 170 & 305,62 & 51955,5 & & \\
\hline & Total & 589 & & & & \\
\hline \multirow{3}{*}{ Educação } & 1 & 371 & 256,99 & 95345 & & \\
\hline & 2 & 158 & 283,8 & 44840 & 26339,000 & 0,043 \\
\hline & Total & 529 & & & & \\
\hline \multirow{3}{*}{ Esporte/ Lazer/ Cultura } & 1 & 368 & 252,64 & 92971,5 & & \\
\hline & 2 & 154 & 282,67 & 43531,5 & 25075,500 & 0,030 \\
\hline & Total & 522 & & & & \\
\hline \multirow{3}{*}{ Transporte } & 1 & 374 & 261,14 & 97665,5 & & \\
\hline & 2 & 161 & 283,94 & 45714,5 & 27540,500 & 0,082 \\
\hline & Total & 535 & & & & \\
\hline \multirow{3}{*}{ Segurança } & 1 & 436 & 300,05 & 130822 & & \\
\hline & 2 & 173 & 317,47 & 54923 & 35556,000 & 0,256 \\
\hline & Total & 609 & & & & \\
\hline \multirow{3}{*}{ Saneamento } & 1 & 420 & 293,36 & 123212,5 & & \\
\hline & 2 & 168 & 297,34 & 49953,5 & 34802,500 & 0,778 \\
\hline & Total & 588 & & & & \\
\hline \multirow{3}{*}{ Habitação } & 1 & 425 & 296,03 & 125812,5 & & \\
\hline & 2 & 167 & 297,7 & 49715,5 & 35287,500 & 0,906 \\
\hline & Total & 592 & & & & \\
\hline
\end{tabular}

Fonte: Elaboração própria com base no projeto de pesquisa "Capital social e políticas públicas em Novo Hamburgo e Estância Velha: subsídios para o desenvolvimento" (CPP/Feevale); ano: 2012.

Como podemos observar, em todas as áreas, na medida em que se passa do nível 1 para o 2 (agora agrupado com o 3), temos sempre um aumento no escore sem exceção, na saúde de 290,69 para 305,62, na educação de 256,99 para 283,8, e assim sucessivamente. Aplicando-se o teste de Mann-Whitney, encontramos significância na educação ( $p=0,043)$, no esporte, lazer e cultura $(p=0,030)$ e muito próximo da significância no transporte $(p=0,082)$. 
No caso de Estância Velha, o fenômeno parece se repetir quando aplicamos os mesmos testes. Observando-se o Quadro 3 do teste de Kruskal-Wallis na variável saúde, quando aumentam os indicadores de capital social, 1 (baixo), 2 (médio) e 3 (alto), também aumentam os escores de satisfação, de 282,62 no nível 1 para 307,94 no nível 2, caindo para 252,96 no nível 3. Entretanto, quando observamos a área da segurança, há certa linearidade: à medida que aumentam os indicadores de capital social 1, 2 e 3, aumentam os escores respectivamente para 291,05, 309,76 e 358,88. O mesmo vai ocorrer na habitação e no saneamento. Aplicando-se o teste, não encontramos diferenças significativas entre os níveis do indicador: 
Quadro 3

Teste Kruskal-Wallis para comparação da satisfação dos serviços públicos entre os níveis do indicador de capital social (Estância Velha)

\begin{tabular}{|c|c|c|c|c|c|}
\hline & I NDCOD & $\mathbf{N}$ & Mean Rank & Chi-Square & P-Value \\
\hline \multirow{4}{*}{ Saúde } & 1 & 330 & 282,62 & \multirow{4}{*}{4,088} & \multirow{4}{*}{0,129} \\
\hline & 2 & 242 & 307,94 & & \\
\hline & 3 & 12 & 252,96 & & \\
\hline & Total & 584 & & & \\
\hline \multirow{4}{*}{ Educação } & 1 & 280 & 242,34 & \multirow{4}{*}{3,953} & \multirow{4}{*}{0,139} \\
\hline & 2 & 212 & 265,81 & & \\
\hline & 3 & 12 & 254,29 & & \\
\hline & Total & 504 & & & \\
\hline \multirow{4}{*}{ Esporte/ Lazer/ Cultura } & 1 & 287 & 253,72 & \multirow{4}{*}{3,525} & \multirow{4}{*}{0,172} \\
\hline & 2 & 212 & 254,97 & & \\
\hline & 3 & 12 & 328,79 & & \\
\hline & Total & 511 & & & \\
\hline \multirow{4}{*}{ Transporte } & 1 & 298 & 265,21 & \multirow{4}{*}{0,107} & \multirow{4}{*}{0,948} \\
\hline & 2 & 220 & 266,58 & & \\
\hline & 3 & 12 & 252,92 & & \\
\hline & Total & 530 & & & \\
\hline \multirow{4}{*}{ Segurança } & 1 & 344 & 291,05 & \multirow{4}{*}{3,598} & \multirow{4}{*}{0,165} \\
\hline & 2 & 243 & 309,76 & & \\
\hline & 3 & 12 & 358,88 & & \\
\hline & Total & 599 & & & \\
\hline \multirow{4}{*}{ Saneamento } & 1 & 335 & 289,46 & \multirow{4}{*}{0,403} & \multirow{4}{*}{0,817} \\
\hline & 2 & 237 & 295,02 & & \\
\hline & 3 & 11 & 304,41 & & \\
\hline & Total & 583 & & & \\
\hline \multirow{4}{*}{ Habitação } & 1 & 341 & 286,89 & \multirow{4}{*}{0,132} & \multirow{4}{*}{0,132} \\
\hline & 2 & 239 & 308,42 & & \\
\hline & 3 & 12 & 332,25 & & \\
\hline & Total & 592 & & & \\
\hline
\end{tabular}

Fonte: Elaboração própria com base no projeto de pesquisa "Capital social e políticas públicas em Novo Hamburgo e Estância Velha: subsídios para o desenvolvimento" (CPP/Feevale); ano: 2012.

Procedendo novamente como em Novo Hamburgo, aplicamos o Mann-Whitney em Estância Velha, conforme Quadro 4. Assim, agrupamos, como naquele teste, os casos do nível 3 de capital alto com o nível 2 que apresentam capital médio: 


\section{Quadro 4}

Teste Mann-Whitney para comparação da satisfação dos serviços públicos entre os níveis agrupados do indicador de capital social (Estância Velha)

\begin{tabular}{|c|c|c|c|c|c|c|}
\hline & I NDMODI F & $\mathbf{N}$ & $\begin{array}{l}\text { Mean } \\
\text { Rank }\end{array}$ & $\begin{array}{l}\text { Sum of } \\
\text { Ranks }\end{array}$ & Mann-Whitney $\mathbf{U}$ & P-Value \\
\hline \multirow{3}{*}{ Saúde } & 1 & 330 & 282,62 & 93263,00 & \multirow{3}{*}{38648,000} & \multirow{3}{*}{0,095} \\
\hline & 2 & 254 & 305,34 & 77557,00 & & \\
\hline & Total & 584 & & & & \\
\hline \multirow{3}{*}{ Educação } & 1 & 280 & 242,34 & 67856,00 & & \\
\hline & 2 & 224 & 265,20 & 59404,00 & 28516,000 & 0,049 \\
\hline & Total & 504 & & & & \\
\hline \multirow{3}{*}{ Esporte/ Lazer/ Cultura } & 1 & 287 & 253,72 & 72816,50 & & \\
\hline & 2 & 224 & 258,93 & 57999,50 & 31488,500 & 0,668 \\
\hline & Total & 511 & & & & \\
\hline \multirow{3}{*}{ Transporte } & 1 & 298 & 265,21 & 79033,00 & & \\
\hline & 2 & 232 & 265,87 & 61682,00 & 34482,000 & 0,958 \\
\hline & Total & 530 & & & & \\
\hline \multirow{3}{*}{ Segurança } & 1 & 344 & 291,05 & 100122,50 & & \\
\hline & 2 & 255 & 312,07 & 79577,50 & 40782,500 & 0,112 \\
\hline & Total & 599 & & & & \\
\hline \multirow{3}{*}{ Saneamento } & 1 & 335 & 289,46 & 96968,50 & & \\
\hline & 2 & 248 & 295,43 & 73267,50 & 40688,500 & 0,559 \\
\hline & Total & 583 & & & & \\
\hline \multirow{3}{*}{ Habitação } & 1 & 341 & 286,89 & 97829,00 & & \\
\hline & 2 & 251 & 309,56 & 77699,00 & 39518,000 & 0,054 \\
\hline & Total & 592 & & & & \\
\hline
\end{tabular}

Fonte: Elaboração própria com base no projeto de pesquisa "Capital social e políticas públicas em Novo Hamburgo e Estância Velha: subsídios para o desenvolvimento" (CPP/Feevale); ano: 2012

Como podemos verificar novamente (como em Novo Hamburgo), em todas as áreas analisadas em Estância Velha, na medida em que se passa do nível 1 para o 2, temos sempre um aumento no escore sem exceção, na saúde de 282,62 para 305,34, na educação de 242,34 para 265,20, e assim sucessivamente nas demais áreas. Aplicandose o teste de Mann-Whitney, encontramos significância na educação ( $p=0,049$ ), na habitação $(p=0,054)$ e muito próximo da significância na saúde $(p=0,095)$. 


\section{Considerações finais}

Este artigo procurou demonstrar o impacto do capital social na avaliação de políticas públicas em duas cidades da região metropolitana de Porto Alegre no Rio Grande do Sul, mais precisamente no Vale do Rio dos Sinos. Nesse sentido, nosso argumento é de que instituições políticas que encontram uma sociedade participativa, solidária e detentora de capital social, portanto fértil socialmente, possuem melhores condições de obter êxito em seus propósitos. Nessa perspectiva, procuramos dimensionar empiricamente a dotação de capital social na região metropolitana de Porto Alegre, bem como a satisfação dessas populações com suas políticas. Em ambas as cidades estudadas, as dotações orçamentárias constituíram-se em elemento importante para explicar a satisfação dessas populações locais. Por exemplo, a dotação de $25 \%$ na área da educação mostrou-se importante tanto em Novo Hamburgo quanto em Estância Velha, pois as pessoas têm avaliado positivamente essa área. Nosso quadro teórico de análise vergado sobre nossa empiria nos leva à compreensão de que, para além das dotações orçamentárias, o capital social tem impactado positivamente sobre as diferentes áreas analisadas nessas cidades. I gualmente, os resultados sugerem que índices altos de capital social são importantes variáveis que ajudam a melhorar o desempenho das políticas públicas municipais, melhorando o desempenho das instituições prestadoras de serviços à comunidade, isso porque os serviços são mais adequadamente acessados, demandados, aproveitados por uma sociedade mais organizada.

Tanto os testes de Kruskal-Wallis como os de Mann-Whitney aplicados em ambas as cidades corroboram a direção desse argumento. O teste de Mann-Whitney demonstra correlação significativa entre capital social e satisfação em três diferentes áreas tanto em Novo Hamburgo como em Estância Velha. Todavia, cumpre assinalar a diferença entre as duas cidades, Estância Velha apresentou um volume maior de capital social, ou seja, tanto relações de confiança interpessoal maiores, como mais diversificadas formas de participação, organização e predisposição à cooperação do que Novo Hamburgo. Esta última, cidade de maior porte, mais industrializada, apresentou menores índices de capital social. Dentro do conceito de capital social, parece ser a confiança interpessoal uma das variáveis que melhor explicam a satisfação com as políticas públicas de maneira geral.

Assim, a partir do exposto e para além das questões orçamentárias, é preciso efetivar políticas que incentivem a criação de capital social nas cidades, quer seja através da criação de espaços de lazer ou de formas alternativas de participação comunitária, para que haja a promoção da composição e, em alguns casos, da recomposição do tecido social, possibilitando, num círculo virtuoso, o fortalecimento das políticas públicas. 
Everton Rodrigo Santos - O autor tem pós-doutorado pela Universidade Federal do Rio Grande do Sul (UFRGS) e doutorado em Ciência Política pela mesma instituição. É consultor e avaliador da Capes, professor da Universidade Feevale e da Universidade Luterana do Brasil, atuando no ensino da graduação e da pós-graduação stricto sensu. Como pesquisador, é vinculado ao grupo de pesquisa "Capital social e desenvolvimento sustentável na América Latina", da UFRGS, ligado ao grupo Metropolização e Desenvolvimento Regional, da Feevale, e ao grupo Cidades: Políticas Públicas, Redes e Sustentabilidade, da Ulbra. E-mail: <evertons@feevale.br>.

Marcello Baquero - O autor tem pós-doutorado pelo Institute of Development Studies da Universidade de Sussex na Inglaterra e pelo Instituto Gino Germani de Buenos Aires, e PhD em Ciência Política pela Florida State Universisy. Atualmente é professor do Programa de PósGraduação em Ciência Política da Universidade Federal do Rio Grande do Sul, coordenador do Núcleo de Estudos sobre a América Latina e editor da revista Debates. E-mail: $<$ nupesal@yahoo.com.br>.

\section{Referências bibliográficas}

Abranches, S. H. de. "Presidencialismo de coalizão. O dilema institucional brasileiro". Dados Revista de Ciências Sociais, vol. 31, n 1, p. 5-34, 1988.

Almond, G.; Verba, S. The civic culture: political attitudes and democracy in five nations. Princeton: Princeton University Press, 1966.

ALVES, E. M. Uma presença invisível: escravos em terras alemãs (1850-1870). In: NUNES, M. F. (org.). Diversidade e política afirmativas: diálogos e intercursos. $2^{a}$ ed. Novo Hamburgo: Feevale, 2006.

ANUÁRIO dA I NDÚSTRIA E do COMÉRCIO DE Novo HAMBURgo. Os patriarcas. Novo Hamburgo: Kadosch, 2001/2002.

BANDEIRA, P. S. Algumas hipóteses sobre as causas das diferenças regionais quanto ao capital social no Rio Grande do Sul. In: CoRreA, S. M. S. Capital social e desenvolvimento regional. Santa Cruz do Sul: Edunisc, 2003.

BAquero, M. "Participação política na América Latina". Revista Brasileira de Estudos Políticos, $n^{\circ} 53$, p. 7-34, 1981.

da UFRGS', 2007.

Democracia e desigualdades na América Latina: novas perspectivas. Porto Alegre: Editora Qual democracia para a América Latina?. Porto Alegre: Editora da UFRGS, 2013.

BoschI, R. R. "Descentralização, clientelismo e capital social na governança urbana: comparando Belo Horizonte e Salvador". Dados - Revista de Ciências Sociais, no 4, vol. 42, p. 655-690, 1999.

BRASIL. Constituição Federal de 1988. [online]. Disponível em:

<http://www.planalto.gov.br/ccivil_03/Constituicao/Constituiçao.htm>. Acesso em: 9 jan. 2008.

Emenda Constitucional 29, de 13 de setembro de 2000. [online]. Disponível em: <http://www.planalto.gov.br/ccivil_03/Constituicao/Emendas/Emc/emc29.htm>. Acesso em: 10 jan. 2008. 
BRESSER-PeReiRA, L. C. "Burocracia pública e classes dirigentes no Brasil". Revista de Sociologia e Política, $\mathrm{n}^{\circ} 28$, p. 9-30, 2007.

CUNHA, L. I migração e colonização alemã. In: PICOLLO, H.; PADOIN, M. (dirs.). História geral do Rio Grande do Sul: vol. 2 - Império. Passo Fundo: Méritos, 2006.

DAHL, R. A. Poliarquia: participação e oposição. São Paulo: Edusp, 1997.

DINIZ, E. Crise, reforma do Estado e governabilidade. Rio de Janeiro: Editora FGV, 1997.

FAORO, R. Os donos do poder. Formação do patronato político brasileiro. Rio de Janeiro: Globo, 1958.

FIgUeiredo, A.; LIMONGI, F. Executivo e Legislativo na nova ordem constitucional. São Paulo: FGV, 1999.

Hall, P. A.; TAYlor, R. C. R. "As três versões do neoinstitucionalismo". Lua Nova, n 58, p. 193-224, 2003.

HolandA, S. B. Visão do paraíso. Rio de Janeiro: Brasiliense, 1992.

Huntington, S. Political order in changing societies. New Haven: Yale University Press, 1968.

IBGE. Dados disponíveis em: <http://cidades.ibge.gov.br/xtras/perfil.php?codmun=431340>. Acesso em: 12 set. 2013.

LAFER, C. O sistema político brasileiro. São Paulo: Perspectiva, 1978.

LANDO, A.; BARRos, E. Capitalismo e colonização: os alemães no Rio Grande do Sul. In: DACANAL, J.; GanzaGA, S. (orgs.). RS: imigração \& colonização. Porto Alegre: Mercado Aberto, 1980.

LEVIN, J.; FOX, J. A.; FORDE, D. R. Estatística para ciências humanas. São Paulo: Pearson Education do Brasil, 2012.

Melo, A. Estado, governo e políticas públicas. In: MıCELI, S. (org.). O que ler na ciência social brasileira (1970-1995): ciência política. São Paulo: Sumaré, 1999.

MoısÉs, J. A. Os brasileiros e a democracia: bases sociopolíticas da legitimidade democrática. São Paulo: Ática, 1995.

MONASTERIO, L. M. Medindo o capital social: uma análise das regiões do Rio Grande do Sul. In: CorreA, S. M. S. Capital social e desenvolvimento regional. Santa Cruz do Sul: Edunisc, 2003.

NoRTH, D. C. Instituciones, cambio institucional y desempeño económico. México: Fondo de Cultura Económica, 2001.

NUNES, M. F. "O negro no mundo alemão: idade, memória e ações afirmativas no tempo da globalização". Tese de Doutorado em Antropologia Social. Universidade Federal de Santa Catarina: Florianópolis, 2009.

OStRom, E. "Collective action and the evolution of social norms". The Jornal of the Economic Perspectives. Nashville, vol. 14, $\mathrm{n}^{\circ} 3$, p. 137-158, 2000.

PASE, H. L.; SANTOS, E. R. Capital social e políticas públicas na América Latina. In: BaQUero, M. (org.). Cultura(s), política(s) e democracia no século XXI na América Latina. Porto Alegre: UFRGS, vol. 1, p. 69-93, 2011. 
POPKIN, S. The reasoning vote. Chicago: University Chicago Press, 1994.

PRZEWORSKI, A. "As instituições são a causa primordial do desenvolvimento econômico?". Novos Estudos, n 72, p. 59-77, São Paulo, jul. 2005.

PUTNAM, R. Bowling alone: America's declining social capital. In: DIAMOND L.; PLATTNER, M. (orgs.). The global resurgence of democracy. $2^{\mathrm{a}}$ ed. Baltimore/London: The Johns Hopkins University Press, 1996.

$\overline{2} \overline{0} \overline{0}$. . Comunidade e democracia: a experiência da Itália moderna. Rio de Janeiro: Editora FGV,

RAmbo, B. Pe. A imigração alemã. In: BeCKER, K. (org.). Enciclopédia Rio-Grandense. Canoas: Editora Regional, 1956.

Ramos, E. H. C. L. Cidades e sociabilidades (1822-1889). In: Piccolo, H.; PadoIn, M. (dirs.). História geral do Rio Grande do Sul: vol. 2 - Império. Passo Fundo: Méritos, 2006.

SAMUeL, P. The reasoning voter. Chigago: University Chicago Press, 1994.

SANTOS, E. R. Democracia e desenvolvimento: desafios da sociedade gaúcha. Ijuí: Unijuí, 2013.

SANTOS, E. R., et al. "Contrastes regionais que fazem diferença no Rio Grande do Sul: capital social e desempenho institucional". Revista Brasileira de Gestão e Desenvolvimento Regional, vol. 6, p. 157$187,2010$.

SANTOS, W. G. Cidadania e justiça: a política social na ordem brasileira. Rio de Janeiro: Campus, 1979.

SCHEMES, C., et al. Memória do setor coureiro-calçadista: pioneiros e empreendedores do Vale do Rio dos Sinos. Novo Hamburgo: Feevale, 2005.

SiedenberG, D. R. Condicionantes político-administrativos do desenvolvimento regional no Rio Grande do Sul: a experiência dos Coredes. In: WITTMANN, M. L.; RAMOS, M. P. Desenvolvimento regional: capital social, redes e planejamento. Santa Cruz do Sul: Edunisc, 2004.

SouzA, C. "Políticas públicas: uma revisão de literatura". Sociologias, Porto Alegre, ano $8, n^{\circ} 16, p$. 20-45, jun. 2006.

TRIBUnAL DE ContAS do Estado [online]. Disponível em:

<http://www1.tce.rs.gov.br/aplicprod/f?p=20001:74:2916824971285883::::: >. Acesso em: jan. 2013.

VIANA, O. Problemas de organização e problemas de decisão: o povo e o governo. Rio de Janeiro: Record Cultural, 1974

WEBER, R. As comemorações da imigração alemã no Rio Grande do Sul: o "25 de julho" em São Leopoldo, 1924-1949. Novo Hamburgo: Feevale, 2004.

"Mosaico identitário: história, identidade e turismo nos municípios da Rota Romântica-RS". Tese de Doutorado em História, Universidade Federal do Rio Grande do Sul: Porto Alegre, 2006. 


\title{
Resumo
}

Capital social e políticas públicas na região metropolitana de Porto Alegre: comparando Novo Hamburgo e Estância Velha

O objetivo deste artigo é analisar as razões que determinam a avaliação satisfatória das políticas públicas em duas cidades da região metropolitana de Porto Alegre: Novo Hamburgo e Estância Velha. Para tanto, construímos um quadro teórico a partir da perspectiva analítica do capital social, que leva em conta os padrões valorativos locais (a cultura política) para a avaliação das políticas públicas. Nossa hipótese de trabalho é de que políticas públicas que encontram uma sociedade organizada, horizontalizada e detentora de capital social possuem melhores condições de obter êxito em seus propósitos. Assim, o capital social constitui-se num aliado às instituições políticas, na medida em que ele as tem impactado positivamente. Os resultados sugerem que índices altos de capital social são importantes variáveis que ajudam a melhorar o desempenho das políticas públicas municipais, melhorando o desempenho das instituições prestadoras de serviços à comunidade. A metodologia utiliza os resultados de duas pesquisas quantitativas, tipo survey domiciliares, aplicadas em Novo Hamburgo e em Estância Velha em 2012, com amostras probabilísticas, totalizando 1.219 questionários, com erro amostral de $4 \%$ e confiança de $95 \%$, bem como pesquisa documental aos sites das referidas prefeituras, IBGE, TCE e FEE.

Palavras-chaves: capital social; cultura política; Novo Hamburgo; Estância Velha

\begin{abstract}
Social capital and public policy in metropolitan region of Porto Alegre: comparing Novo Hamburgo and Estância Velha

This article investigates the satisfactory evaluation of public policies in two cities in the suburban region of Porto Alegre, Brazil: Novo Hamburgo and Estância Velha. We developed a theoretical framework from the analytical perspective of social capital which takes into account the local value patterns (political culture) for the evaluation of public policies. The hypothesis is that public policies in a society detaining social capital have better conditions to succeed in their objectives. Thus, social capital becomes an ally to political institutions, having a positive impact on them. The results suggest that high levels of social capital are important variables that help improve the performance of public policies and of institutions providing services to the community. Data come from two surveys conducted in the cities of Novo Hamburgo and Estância Velha in 2012, with random samples totalizing 1.219 interviews.
\end{abstract}

Keywords: social capital; political culture; Novo Hamburgo; Estância Velha

Artigo submetido à publicação em junho de 2013. Versão final aprovada em janeiro de 2015. 